\title{
Vocabulary Glossing: A Comparison between L1 Gloss and L2 Gloss in EFL Context
}

\author{
Hussein Meihami ${ }^{1, *}$, Bahram Meihami $^{2}$ \\ ${ }^{1}$ Department of English Language Teaching, Ghorveh Branch, Islamic Azad University, Ghorveh, Iran \\ ${ }^{2}$ Department of Accounting, Ghorveh Branch, Islamic Azad University, Ghorve', Iran \\ *Email address: hussein.meihami@yahoo.com

\section{ABSTERACT} \\ This paper describes a study exploring the effect of vocaby ary sing, L1 gy ss, L2 gloss and
} no gloss, on L2 vocabulary learning. A total of 60 intermedi ranian dents participated in this study. They were divided into three groups: Group one r whr student a text that its new vocabularies were glossed in L1 (Persian); Group two in vhich new vocabularies were glossed in L2 (English) and group three with No gloss provided. Each roup was goi g to take a vocabulary test at the end of the study based on the provided vocabulary ses durin the study. For the purpose of this research a pretest posttest design was run. The compa be the three groups pinpointed that No glossed condition had significant dif with L1 and L2 glossing, but there was no significant difference between L1 and L2 voca ular ing even though the mean score in L1 glossing condition had improved more than L2 gl ng coy dition in the posttest. It was also revealed that EFL students had positive attitud rd L1 v cabulary glossing.

Keywords: Vocabulary learnin

\section{INTRODUCT}

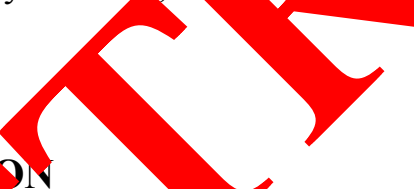

Acco to avies done by scholars (e.g., Day, Omura, \& Hiramatsu, 1991; Dupuy \& Krashen, 1993, רser, 19 9; Paribakht \& Wesche, 1999; Wode, 1999) an L2 learner can learn vords id itally while reading. On the other hand, others like Nagy, 1997; $\mathrm{Na}$ n, 20 1; Sokm n, 1997; Stein, 1993suggests that learning words from context while focu $g$ is an inefficient method because of the limitations inherent in deriving meanin. from contextual cues. As Hudson (2007) stated, it still is not clear how incidental vocabular, arning occurs or what amount of exposure is required for readers to learn these words. Vocabulary glossing has been found to be conducive in L2 vocabulary learning. Vocabulary glossing has two types: L1 glossing in which students are provided with a list of vocabularies that their definitions have been given in students L1, for example students with Persian first language who are learning English vocabularies are provided with Persian definition of those vocabularies. On the other hand, L2 glossing is another types of vocabulary glossing in which students are provided with L2 definitions of new vocabularies, for instance, students with Persian first language who are learning English vocabularies are provided with English definition of those vocabularies. The current study examines the effect 
of glossing on L2 vocabulary learning. In this study both types of glossing have been examined. In this study, students' opinions about different types of glossing have been investigated.

\section{1. Review of Literature}

Glossing is considered as one type of input modification that is a pedagogical intervention in which a teacher manipulates a target form to help learners acquire the form (HEE KO 2012). For instance, reading passages in second language learning are often modified to meet the learners need. The structures of text are manipulated and vocabulary items are controlled to enhance comprehension and thus learning (Larsen-Freeman \&-I ong, 1991). A number of studies have compared a simplified version with an elabor ced ver n using listening materials (e.g., Chaudron \& Richards, 1986; Chiang \& Dunke 1992; Kelt 1985 ) as well as reading passages (e.g., Johnson, 1981; Oh, 2001; Stroth \& in, 198 Likewise, glossing can be used as modified input to facilitate vocabul y learning $\mathrm{v}, \mathrm{O}$ viding additional information such as definitions or synonyms, glos o help studen cope with insufficient contextual cues in learning new words while readio.

A number of studies have looked at the effect of input $m$ dification L2 vocabulary learning using glossing. However, the design of these studie is verse due cheir different purposes in examining glosses. Holly and King (1971) po pare fferent types of glosses depending on the place where a gloss is presented, sucb as de of pas hottom of page, or on an attached sheet. Hulstijn, Hollander, and Gr danus (1996) isvestigated incidental vocabulary learning using marginal glosses and di onaries. Th/y also tested the effects of word frequency, either once or three times in the tex Julstijn (992), Watanabe (1997), and Nagata (1999) were interested in investigeting the en multiple-choice (MC) glosses with other types of glosses or input, such as tive, single-gloss, and no-gloss conditions. Rott, Williams, and Cameron (2002) examin d t $\mathrm{t}^{t}$ of a first language (L1) MC gloss and L2 text reconstruction on lexicalacquisitic and retention and text comprehension.

In addition, the effect of $\mathrm{La}$ a 2 gl ses also was compared in a few published studies: Jacobs, Dufon, and 5 (19 4) with yaper-based texts, and Laufer and Hill (2000) and Yoshii (2006) in a mu nea ent. Jacobs et al. compared the effect of L1 and L2 glosses with Spanish the fore $r_{0}$ anguage. They tested L1 gloss, L2 gloss, and no-gloss conditions on 85 nat e $s_{1}$ ers of En, sish enrolled in a fourth-semester Spanish course in a U.S. university. A tereadin passage, students were asked to recall the passage and translate the glosser vocabulary fro Spanish to English. They did the translation again after 4 weeks. The cults $\mathrm{w}$ that the original glossing did not have any significant effect in helping them the $\mathrm{p}$ sage. On the immediate vocabulary translation test, there was a signifio differ be ween the gloss groups and the no-gloss group. However, there was no gnifi nt difto ace between the L1 gloss and L2 gloss groups. On the delayed voc. lar ar a n after 4 weeks, no significant difference was discernible between the gloss os ana the no-gloss group, or between the L1 gloss and L2 gloss groups.

Yo. 2006) compared the effectiveness of L1 and L2 glosses along with pictorial cues in a nultimedia environment. The study involved 195 Japanese university students. Yoshii assumed that they belonged to a low-intermediate or intermediate level. A week before the experiment, students took a vocabulary pretest, a recognition test containing 14 tar-get words and 10 additional distracters. While reading a 390-word story, including the 14 target words, students could click a gloss and look up four types of glosses on the screen when needed: L1 gloss, L2 gloss, L1 gloss with a picture, and L2 gloss with a picture. After they finished the reading, an immediate vocabulary test (definition-supply test in the Lland recognition test in the L2) was given. After 2 weeks, a delayed vocabulary test with the same 
format was given. The results show that, regarding the definition-supply test, L1 and L2 gloss groups did not show a significant difference between the immediate and delayed vocabulary tests. However, in the case of the recognition test, the L2 gloss group dropped significantly on the delayed vocabulary test.

On the whole, more studies comparing L1 and L2 glosses are necessary. The reason is that the comparisons between L1 and L2 are still limited: Jacobs et al. (1994) compared English and Spanish, Yoshii (2006) compared Japanese and English, and Laufer and Hill (2000) compared Hebrew, Chinese, and English. Moreover, there are concerns that have not been addressed. For example, Jacobs et al. and Yoshii found no significant differences between L1 and L2 gloss groups on an immediate vocabulary test. However, according to Laufer and Hill, Hong Kong learners showed a significant difference between thes ss types, whereas Israeli learners did not. It is unclear what conditions are and are differential among these groups. Given that the number of studies is gan imited at important questions are still unanswered, replications are needed in order corrity resu of previous studies and to provide better insights into this area.

This study is designed to investigate the effect of L1 and L2 glos an No g ss on L2 vocabulary learning in a six week period. In this study in the connt of the rogm a pretest was held and at the end of the program a posttest was to indic th changes in students' vocabulary learning. At the end of program the wa question aire to survey students' preference about L1, L2 or No glosses.

This study is going to investigate the fallowing uestion:

A) Is there a difference in vocabulary learning tween the L1, L2, and No glosses in an EFL context?

B) What are learners' opinions about different glo

\section{METHOD}

\section{1. Participant}

A total of 60 interm anglish Academic Institute in Qazvin, Iran all male and ranging in age rom 18 to years participated in this study. All of these students were originally from an anglish as a foreign language for them. The participants were recruited to volurta y par inate in an English Vocabulary Learning Program (EVLP). These 60 stude its who were Atermediate level of proficiency were descended from 89 students wh partic ted in rocabulary proficiency test that was administrated by the institute prion start $f$ program to rank different level of proficiency. According to obtaine ores, stud ents were in upper-intermediate level of proficiency, 3 were in ady iced vel of I ciency, and 16 were in pre-intermediate level of proficiency with reg. to inclish ocabulary knowledge. For the purpose of this study, 60 intermediate studen vere crrosen to test the research question on them. They were divided into three groups a included 20 students. Each group got on glossing condition based on three glossing co, idition, L1 gloss, L2 gloss, and No gloss. Three experienced non-native teacher were responsible to teach English vocabulary based on the specific glossing conditions. The EVLP took about 6 weeks and there were 12 sessions of it. Students attended two sessions each week. The duration of each session was one and a half hour. 


\section{2. Materials}

Some reading texts from "Read and Understand" (Betty Kirkpatrick, Rebecca Mok) were chosen for students in which the proficiency level of texts suited with the participants level. The feature of these texts was that they could be used for each group. For the first group there was provided L1 gloss (See Table 1) for each unit in Persian; it was participants' first language.

Table 1. L1 Gloss.

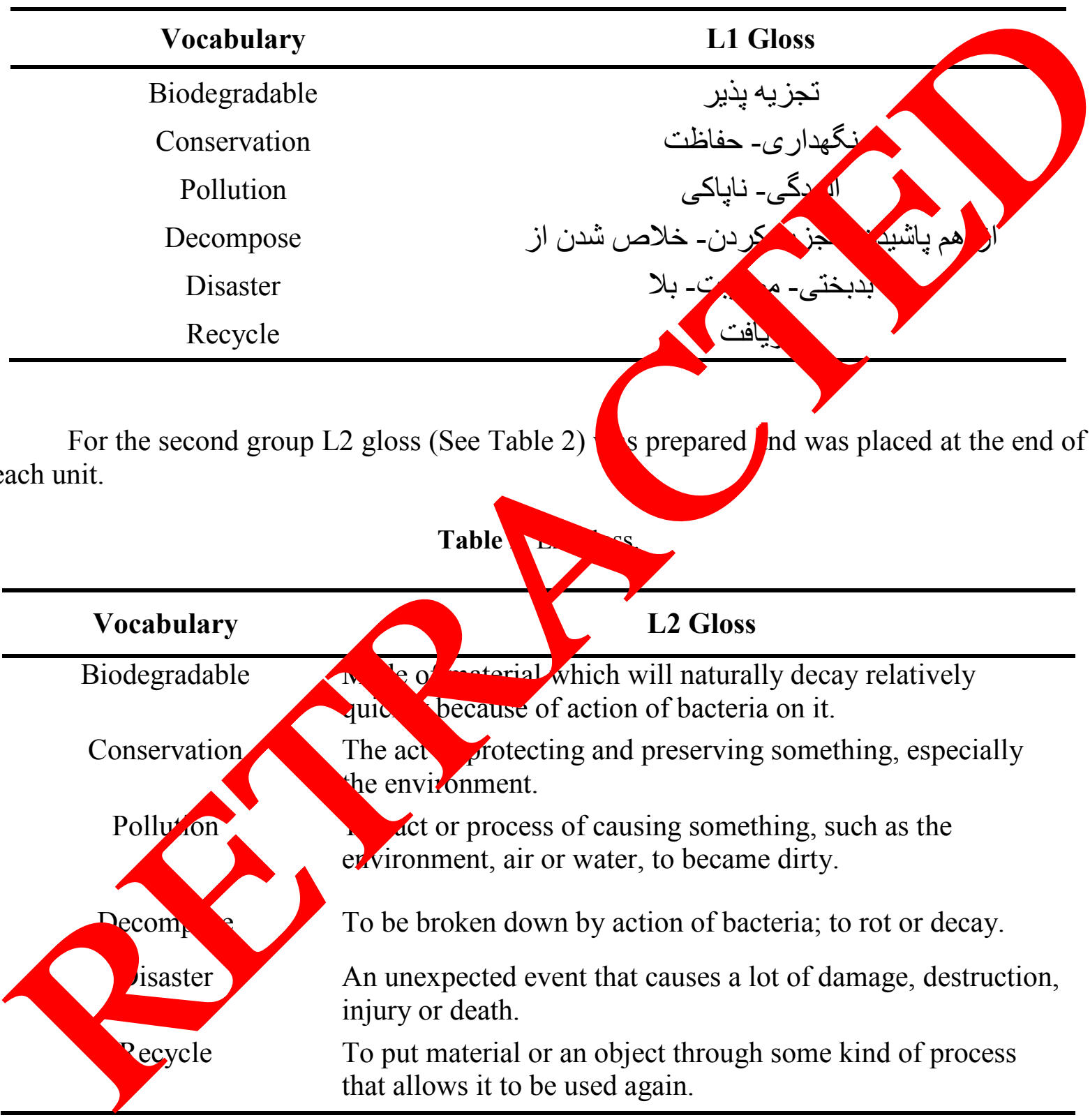

In the third group, the control group, there was no vocabulary gloss not in L1 or in L2 and the students were responsible in looking up each unit new vocabulary. The researcher also prepared two cloze tests in participants' proficiency respect.

One of those tests was administrate at the beginning of the program for the reason of identifying students' proficiency level and one at the end of the program to capture the trend of students' change in their proficiency level, if any. In this study SPSS16 was used to improve the accuracy of analyzing data. 


\section{3. Procedure}

A total of 60 Iranian EFL students who were in intermediate level of proficiency in regard with English vocabulary participated in an English vocabulary Learning Program that was provided by English Academic Institute sited in Qazvin, Iran. During six weeks students in three groups were under vocabulary instruction based on three vocabulary glossing: L1 glossing, L2 glossing, and No glossing. In the first group L1 vocabulary gloss of each unit new vocabularies was provided for students to learn about them.

The second group was the same as the first one with this difference that the L2 vocabulary gloss was prepared for students of this class for learning new vocabularies. The third group has a basically difference and it was that in this group no gloss was premand for students and they were responsible for looking up the vocabulary by thems $v$ es. In beginning of each session, students in group one and two were allowed study th provided vocabulary glosses in L1 and L2 and then read the text and do its verc

There was limited time for students to study the glosses; the allott a time wa out 20 minutes for each gloss that contained about 10 new vocabularies. Yo in the ird gr $\rho$ the situation was quite different. Students were given the same tex an "is but ey were responsible to look up new vocabulary by themselves.

They were allowed to use bilingual or monolingual Teachers were supervisor in all groups. They were reco nsiblo helping students with vocabularies' pronunciation, and controlling the corres arc of the es ases and doing some pre-reading and post-reading activities.

The teacher of third group, No gloss group, as also resp nsible for helping students with finding new vocabularies in their dictionaries. or to the art of the program a pretest in the type of cloze test was administrated for two p. cirst, to assure researcher that the proficiency level of the participants $\mathrm{W}$ same level and they are homogenous; second, to obtain the beginning level of stu lent the obtained mean score for future
comparison.

In session 15, a test of saden prefer ce in glossing and glossing type was held (Table 3). The result of this will se discus,ed in the result section. At the last session, session 16, the posttest a arouns. The obtained data then was transferred to SPSS to b valyzed.

\section{RESULT}

As it wa earlie prior to the start of the program a vocabulary proficiency test was admini gro for to assure the researcher that participants were within the same real of ficienc, $n$ regard with English vocabulary. Table 3 is showing the obtained

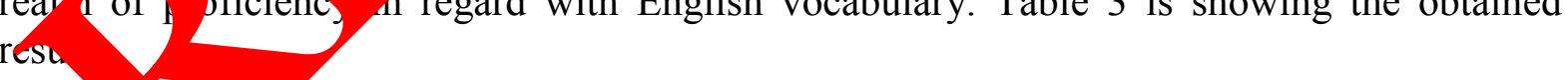


Table 3. Descriptive Statistics for Vocabulary Proficiency Test.

\begin{tabular}{cccccc}
\hline Group & N & Minimum & Maximum & Mean & Std. Deviation \\
\hline L1Gloss & 20 & 34.00 & 90.00 & 57.8500 & 14.37569 \\
L2Gloss & 20 & 42.00 & 88.00 & 58.0500 & 14.84118 \\
No Gloss & 20 & 39.00 & 92.00 & 59.3500 & 15.85465
\end{tabular}

Valid N (list wise) $\quad 20$

As it is clear with the comparison of the obtained means scale on can we conclusion that all groups were in the same level of vocabulary prof ncy he be aning of the program. This fact is a good prove for the effectiveness of pro ency te that was administrated to divide participants to different proficien groups. his vocabulary proficiency test was also used as a pretest to be compared wi th osttest.

The alpha level for all statistical analysis was set 9.05. one-way ANOVA was conducted to analyze group differences in performan c on the posttes the reliability of the posttest vocabulary test was 0.84 , measured by Cron ach's alpha. Table 4 intends to show the descriptive statistics of posttest.

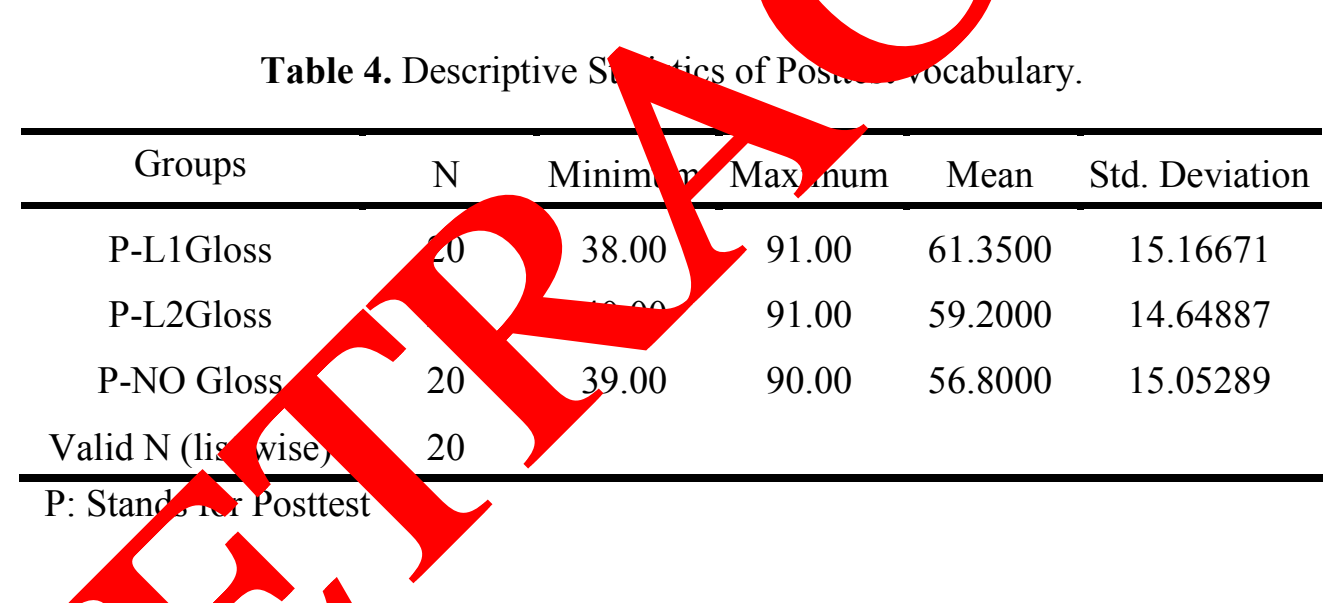

Table 4 this fa that the mean score of L1 gloss (61.35) has improved more than the mores 20 oss (59.2). Yet, the decrease in mean score of no gloss condition is qui inter sting. Ty result of a one-way ANOVA indicated that there was a significant diftu the conditions $(\mathrm{F}(2,103.61)=0.63, \mathrm{p}<0.5)$. For the purpose of indicat the specific place of significance, a Scheffe's post hoc analysis was conducted. This test wed the significant difference between the no gloss condition and the glossed conditions, nevertheless, there was no significant difference between the L1 and L2 gloss conditions. A paired t-test was conducted for each type of gloss condition to see if there is any significant vocabulary learning in any of gloss conditions. The paired t-test indicated that there was no significant effect in the no gloss condition $(\mathrm{t}(19)=.23, \mathrm{p}>.5)$. However, there were significant differences in L1 and L2 glosses condition. 
There was also a test of gloss preference among participants to indicate the percentage of each gloss condition preference among participants. Table 5 illustrated the obtained data.

Table 5. Participant Preference in Glossing Condition.

\begin{tabular}{cc}
\hline Gloss Condition & Percentage of Preference \\
\hline L1 Gloss & $60 \%$ \\
L2 Gloss & $26 \%$ \\
No Gloss & $5 \%$ \\
Others & $9 \%$ \\
\hline
\end{tabular}

As Table 5 illustrates L1 vocabulary glossing had got highest p age $(60 \%)$ and was the most acceptable technique of vocabulary glo ing cted by articipants. L2 vocabulary glossing was in the second place of favori arsed on participants' desire. With $26 \%$ of desirability percentage, L2 vocabular glossing can be onsidered for second thought in the EFL vocabulary learning context. Fi ally, no gloss condition with just 5\% of acceptability was the lowest among the three grot The que tionnaire also sought other preferable techniques like teacher translating meanin. amput r-assisted language learning, association of meaning, and etc. The obtai mercentag $(5 \%)$ of these techniques showed that using these techniques can be effective a d thr opod subjects for future researches.

\section{DISCUSSION}

The results of this nvestiga support that vocabulary glossing in has a significant effect on vocabulary/a. $\mathrm{ng}$ in the context, thus supporting the findings of previous investigation (Laufe \& h tijn, 2061; Schmidt, 1993; Yoshii, 2006). The first research question was: Is r1oe a differ $\mathrm{in}$ vocabulary learning between the L1, L2, and No glosses in an EFL co text? he results showed that there is a significant difference between glossed condition anc $\mathrm{g}^{1}$ sssed o ndition. Based on the results, participants in the glossed condition had better voca ry lea ang at the end of the program than those of no glossed condition. This ana is sim the findings of Myong Hee (2012). The mean score for L1 and L2 $\mathrm{gl}$ in he pretes were 57.85 and 58.05 respectively and this amount reached 61.35 and 59.20 dest that crystal clearly shows improvement in participants of glossed conditio roups' vocabulary learning. However, the mean score for no glossed condition at the pretest me was 59.35 and with a considerable decrease it became 56.80.

The rational reason for the L1 glossed condition increase in mean score is that in EFL context the translating is the core technique in conveying meaning of the new vocabulary. By so doing, it became a habit of learning for students and they grabbed it in their learning of new materials such as learning vocabulary. The participants' preference in choosing L1 gloss as the desired gloss is a good prove for this claim. It seems that guessing words from context which is used by no glossed condition group has no effective impacts on vocabulary learning in the EFL context but it also has a reverse effect. The previous studies also showed that guessing on unknown vocabulary may not be effective (Aebersold \& Field, 1997; Ko, 2012). 
Another explanation of why learners performed better on the glossed text according to Ko (2012) may be related to the effects of input modification. Learners may have had a better chance to have their attention drawn to the targeted vocabulary when glosses have been prepared for them. Regarding comparison between L1 and L2 glossing, the result of this study contrast with those of Yoshii (2006) and Ko (2012) in that L2 glossing had the significant impact on vocabulary learning of EFL students, yet in this study it was concluded that L1 due to some educational system principles had a significance effect on the vocabulary learning of EFL students.

The second question of the current investigation was: What are learners' opinions about different glosses types? For answering this question Table 6 is quite comprehensive in which it showed that $60 \%$ of participants desired L1 gloss, $26 \%$ desired L2 gloss, $5 \%$ no gloss, and $9 \%$ desired other types of vocabulary learning. The simple fact here s student EFL context and especially in Iran has a method of translating for their vocau v learnit so this translating method has become a habit of their learning and for ow th are ve $y$ convenient with L1 glossing and as one compare their mean score in th $\mathrm{L} 1 \mathrm{~g}$ ssed o $\%$ ion was higher than that of other vocabulary glossed condition. As Ru $(20,7)$ an 1 /arhadi (2000) stated the system of language learning in Iran is not for ormun tive py poses but to translating and L1 gloss is the best method of achieving this

\section{CONCLUSION}

The aim of this study was to investigate $t$ effect of lifferent glossing types on learning L2 vocabulary in an EFL context [15-22]. To the conclusion on this aim, first a comparison have done between the no glos andition and glossed condition. The findings showed that while no glossed condition ha no on L2 vocabulary learning; glossed condition has a positive effect on L2 vocab lory leaning; thus the results are supporting previously done research on thi (Jacob 1994; Yoshii, 2006; Ko, 2012); and then another comparison was done ${ }^{\prime}$ ween he two o ossing condition.

This study also shows on previously done research on whether L1 gloss is more effective in $4 \mathrm{~L}$ con or L2 gloss for learning new vocabulary. This investigation's answer a quest $\downarrow<1$ gloss based on the comparing means of the tree glossing condition. et, ou like Ko (2012) and Nagata (1999) indicated that L2 gloss is more effective ir $\mathrm{D}$ vocabula

A third ompa son was gone about the among the participants preference on glossing types that au ding to thesults L1 gloss was in the first place of desirability. It was discussed that th Tesirab ity of L1 gloss may because of the system of L2 education in EFL coun ues. 2 glos placed after L1 gloss, yet it is important for teachers to use this gl ng ty e becaus of the fact that it had a relatively high desirability percentage.

study devoted its own purpose to study the glossing types in vocabulary learning th regard to intermediate EFL students. It is important to note that the context of the researy was EFL and the participants were in intermediate level of proficiency, so further researches examining other proficiency level and ESL context regarding the different glossing types would be useful follow up to this study. Future researches need to access whether the processing of L2 vocabulary learning triggered by glossing condition lead to long-time vocabulary retention and learning. The pedagogical implication of the finding of this study for L2 vocabulary learning in EFL context is that vocabulary glossing condition in L1 or L2 would be excellent means to teach students about new vocabulary of L2. So it is important for teachers and language planers to consider these vocabulary glossing conditions in their perspective of teaching new vocabularies. 


\section{References}

[1] Aebersold J. A., Field M. L. (1997). From reader to reading teacher. New York, NY Cambridge University Press.

[2] Alco' n E., International Review of Applied Linguistics 36 (1998) 343-362. doi:10.1515/iral.1998.36.4.343

[3] Barcroft J., Applied Language Learning 13(2) (2003) 47-73.

[4] Bowles M. A., Hispania 87 (2004) 541-552. doi: $10.2307 / 20063060$

[5] Day R., Omura C., Hiramatsu M., Reading in a Foreign Language 7 (1991)

[6] Huckin T., Coady J., Studies in Second Language Acquisition 21 (1991) 18 doi:10.1017/S0272263199002028

[7] Hudson T. (2007). Teaching second language reading. New Yorl Y: O rd University Press.

[8] Laufer B., Hulstijn J., Applied Linguistics 22 (2001) 1-26 doi:10.1093/applin/22.1.1

[9] Nagata N., Foreign Language Annals 32 (1999) doi:10.1111/j.1944-9720.1999.tb00876.x

[10] Rott S., Williams J., Cameron R., Language T thing Resed fch 6 (2002) 183-222. doi:10.1191/13621688021r108oa

[11] Taylor A., Reading in a Foreign Langt a(1) (2006) 72-73.

[12] Thornbury S. (2002). How words are led nd? lis. Harmer (Ed.), How to teach vocabulary (pp. 13-31). Harlo England Pearson Education.

[13] Wong W. (2005). Input e ance ent: Fro theory and research to the classroom. New York, NY: McG $\mathrm{W}-$

[14] Yoshii M., Langy Learning Technology 10(3) (2006) 85-101.

[15] Monirosadat H sein, "ohamad Ehsan Taghizadeh, Mohamad Jafre Zainol Abedin, Elham Nas 11, Internatio Jetters of Social and Humanistic Sciences 6 (2013) 1-12.

[16] Husse Meib in Mternational Letters of Social and Humanistic Sciences 8 (2013) $8-23$.

[17) Hus in Men, International Letters of Social and Humanistic Sciences 8 (2013)

[18] h ein Meihami, Bahram Meihami, Zeinab Varmaghani, International Letters of Soct and Humanistic Sciences 8 (2013) 57-65.

[19] Hussein Meihami, Zeinab Varmaghani, International Letters of Social and Humanistic Sciences 9 (2013) 49-58. 
[20] Hussein Meihami, Bahram Meihami, Zeinab Varmaghani, International Letters of Social and Humanistic Sciences 11 (2013) 47-56.

[21] Hussein Meihami, Bahram Meihami, Zeinab Varmaghani, International Letters of Social and Humanistic Sciences 11 (2013) 57-65.

[22] Monirosadat Hosseini, Mohamad Jafre Zainol Abidin, Hamid Kamarzarrin, Mohamad Khaledian, International Letters of Social and Humanistic Sciences 11 (2013) 66-75.

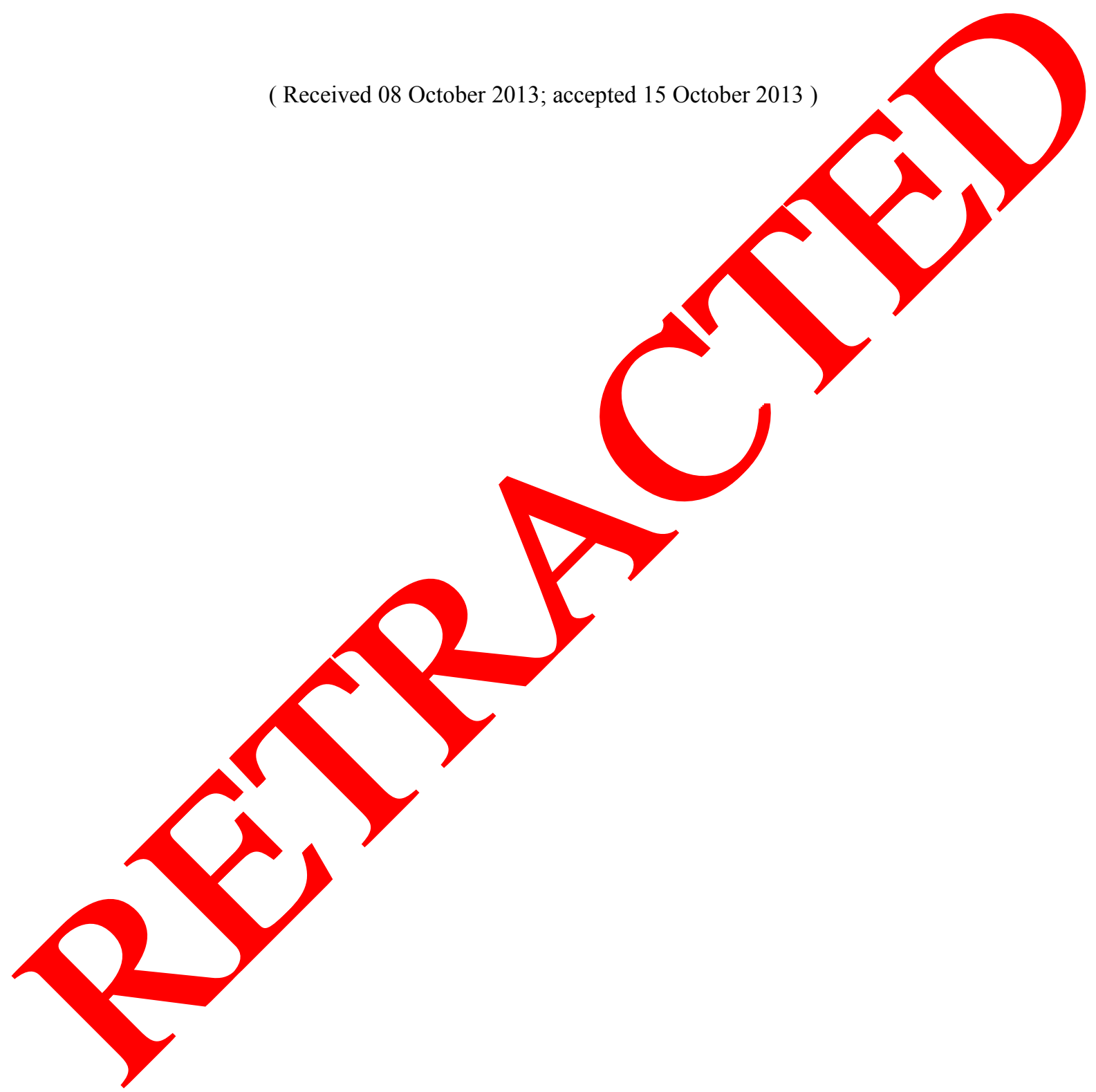

